\title{
Older people's perspectives on an elderly-friendly hospital environment: an exploratory study
}

This article was published in the following Dove Press journal:

Risk Management and Healthcare Policy

13 May 2015

Number of times this article has been viewed

\section{Sushmita Karki \\ Dharma Nand Bhatta ${ }^{1,2}$ \\ Umesh Raj Aryal ${ }^{3}$ \\ 'Department of Public Health, Nobel College, Pokhara University, Kathmandu, Nepal; ${ }^{2}$ Faculty of Medicine, Epidemiology Unit, Prince of Songkla University, Songkhla, Thailand; ${ }^{3}$ Department of Community Medicine, Kathmandu Medical College, Kathmandu, Nepal}

Video abstract

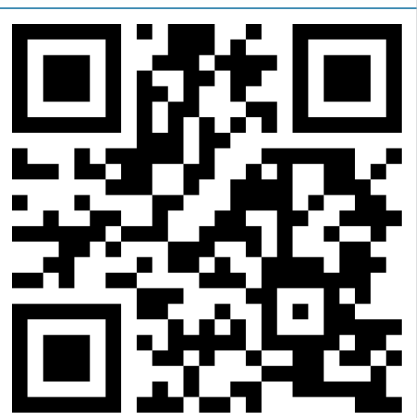

Point your SmartPhone at the code above. If you have a QR code reader the video abstract will appear. Or use: http://youtu.be/qaYv5Gd4fqg
Correspondence: Dharma Nand Bhatta Department of Public Health, Nobel

College, Pokhara University, Sinamangal, Kathmandu, Nepal

Tel +977984l48 5l28

Emaildnbhatta@yahoo.com
Background: Many older people are vulnerable with multiple health problems and need of extensive care and support for quality of life. The main objective of this study was to explore the older people's perspectives on an "elderly-friendly" hospital.

Methods: Hospital was stratified by four domains including government, semi-government, community, and private. We interviewed 33 hospitalized older patients and four hospital managers between June and December 2014 in Kathmandu, Nepal, using purposive sampling technique. We executed a qualitative content analysis step with extensive review of the interviews. Final name of the theme was given after the agreement between the research team and experts to improve trustworthiness. Elderly-friendly services, expectation from government and hospital, and health policy related to senior citizen were developed as main themes.

Results: Most of the participants were satisfied with the behavior of health personnel. However, none of the health personnel were trained with geriatric health care. Elderly-friendly hospital guidelines and policy were not developed by any hospitals. Older people health card, advocacy for older people's health and benefit, and hospital environment were the common expectations of older patients. Government policy and budget constraint were the main obstacles to promote elderly-friendly health care services.

Conclusion: Elderly-related health policies, physical environments of hospital, elderly-friendly health manpower, advocacy, and other facilities and benefits should be improved and developed. There are urgent needs to develop elderly-friendly hospital policies and guidelines that focus on older people's health benefits and friendly services.

Keywords: elderly-friendly hospital, older, policy, advocacy, hospital environment

\section{Background}

Globally, the population of "older person", aged 60 years or above, increased from $9.2 \%$ to $11.7 \%$ from 1990 to 2013 , and up to 2050, this number will be increased to $21.1 \% .^{1}$ Among them, nearly eight out of ten will live in low- and middle-income countries by 2050 . In developing countries like Nepal, due to increased life expectancy, the population of older age group is in increasing trends. In 2013, a total of $7.6 \%$ older people were living in Nepal. ${ }^{1}$ Increasing trend of this population will impact on health and economy. ${ }^{1}$

Old-aged people are more vulnerable than other people and more at risk for lengthy stay in hospital. Day-by-day increased number of morbidity among older people accentuates the need to establish elder friendly hospital. ${ }^{2,3}$ Complex and chronic health problems are common in older people; therefore, there is a need to expand trained professional for older care, follow a multi-approach method of treatment, and build a comprehensive team for treatment and care of older people. ${ }^{3-5}$ Previous literature 
revealed that different elements could be considered to make treatment process easy for older people, such as lights, wards, surfaces, signals, and colors in hospital. ${ }^{6}$ Along with this effective communication, motivation, moral supports, and pleasant environments are required in older care settings. ${ }^{7-9}$ Furthermore, older patients faced physical discomfort with different quality of beds, difficulties in mobility, and anxiety due to unpleasant environment while staying for long period in hospital. ${ }^{10}$ Moreover, advances in medical technologies and drastic change in lifestyle of people have also been contributing to demographic shift in population phenomenon. ${ }^{11}$ Serious disparities in elderlyfriendly health care have been found compared to health care for other people. ${ }^{12}$

Previous studies revealed that one-third of the older patients showed decline in physical functional capacity and most of them were unable to recover from the problems due to poor hospital practices. ${ }^{13,14}$ In addition, older person has dissatisfactions and concerns related to treatment or care settings, hospital environments, treatment process and communication, motivation, finances, emotional supports, and health professional's attitudes and behaviors. ${ }^{15-17}$ Furthermore, hospitalization could also effect on the quality of life, working ability, and desire for living longer for the older population..$^{2,18,19}$ However, this drift depends on quality of care, hospital environment, and quality of health personnel..$^{20,21}$ Previous literatures suggested that most of the hospital admissions are unsuitable for older patients..$^{22,23}$ Based on the facts, various countries from Africa, Europe, and America have developed guidelines for quality of elderly-friendly hospitals that covered training and physical environments. ${ }^{24}$

Elderly-friendly health-related policy and programs are necessary for the enhancement of quality health care services in hospitals. ${ }^{10,11}$ Previous findings have suggested the need to develop a protocol of health care services which could reduce harmful circumstance related to older patients. ${ }^{11}$ In Nepal, there is no written documentation related to elderlyfriendly hospitals. However, the government of Nepal has endorsed policies and programs related to senior citizen. ${ }^{25}$ There are sparse literatures and research available related to elderly-friendly hospitals in Nepal. Therefore, it is necessary to understand older peoples perception related to hospital environment which could be the initiation to develop the guidelines, policies, and programs related to elderly-friendly hospitals and health care services in Nepal. The aim of this study was to explore the older people's perspectives on an elderly-friendly hospital in Nepal.

\section{Methods}

\section{Study settings}

This qualitative study described and explained on the perspectives of older patients on elderly-friendly hospitals in Kathmandu, Nepal, between June and December 2014.

This study theme was generated based on the information provided by older peoples who were admitted in the hospital and hospital managers from government hospital, community hospital, semi-government teaching hospital, and private hospital situated in Kathmandu district of Nepal. This study was conducted to scratch the situation of elderly-friendly hospitals in Nepal through the opinions of hospital managers and older patients.

\section{Participants}

Firstly, list of the hospitals was collected and categorized by four domains including government central level, community, teaching, and private hospital from the ministry of health and population. One hospital was selected from each domain using random sampling technique. Secondly, participants were selected using purposive sampling technique from inpatient departments of all the hospitals. One key informant interview was taken from each hospital. We selected one hospital manager from each hospital as a key informant. Research team made an appointment with potential participant's available time and place. The inclusion criteria for the participants were i) age above 60 years, ii) admission in the hospital, iii) ability to communicate, and iv) willingness to participate in this study.

Further, sampling and analysis were carried out concurrently. Through the purposive sampling method, 33 participants were interviewed from all the hospitals. Among the total, ten participants were interviewed from government hospital; similarly, nine, eight, and six participants were interviewed from semi-government teaching hospital, community hospital, and private hospital, respectively. However, sample size was determined by data saturation. Totally three participants (one was from community hospital among nine participants, and two were from private hospital among eight participants) refused to participate in the interview.

\section{Data collection methods}

Pilot study was conducted before initiation of real interview. Two participants were taken for in-depth interview in the pilot study, and after that, interview guidelines were modified.

Data were collected through in-depth interviews conducted in Nepali by three public health graduates. We trained 
the interviewers in using recorder and note taking. Informal and formal ways of interview were conducted with the help of semi-structured guideline. Several interviews were carried out with potential participants in order to support data analysis. Second interview was taken with the participants if the first interview lacked sufficient clarification of the information. All the interviews were tape-recorded, and at the same time, note taker had taken the notes. Interview process had taken an average of 40 minutes. Data were collected based on the main research question, and it was probed by moderator to clarify the participants. Other sub-questions were developed to meet the objectives of the study. The main questions were as follows: How would you describe your experience of the situation of elderly-friendly hospitals in Kathmandu? What are the main expectations from the hospital?

Next, four key informant interviews were conducted with each hospital managers. All the tape-recorded interviews were transcribed in Nepali and converted into English. All the interview processes had taken an average of 50 minutes. Information was collected based on the following main research questions: Could you explain the special services that are offered at your hospital for older patients? Does your hospital have any guidelines or policy related to elderlyfriendly hospitals?

\section{Data analysis}

Information was extracted from tape record and transcribed into English. Content analysis process of qualitative study was performed that maintained the validity, reliability, and consistency of the materials, and Colaizzi process for phenomenological data analysis was followed. ${ }^{26,27}$ Two authors (SK and URA) identified code from all the transcribed data. Underlined words and sentences were rechecked by other researcher (DNB), and the final code was confirmed. Analysis was done with NVivo version 8 software. ${ }^{28}$

Firstly, coding was done rigorously and carefully integrated into both examination and interpretation of data. Theme, patterns, and characteristics of the events were analyzed and were developed based on the coding. Researchers had read transcribed file very clearly and had underlined the key words. All the transcripts had been read and highlighted line by line and word by word which had produced important categories.

Secondly, after finding out the underlined key words, appropriate code name was given to symbolize it. Code was written in the right hand side of the transcript after indentifying the highlighted key words. Code name was produced through the participant's information. Common code was interconnected with the other transcription, which was compared and contrasted with the analysis. After reading the transcript, research team members made consensus on extracting the significant key words and code.

Thirdly, significant statements were used to originate meanings. Concepts were identified and named. Concepts were developed under the same categories that shared common characteristics. Each underlying meaning was coded in one category in which it had similar information, and others were placed under the subcategories. Research members then compared the developed meanings with the original meanings in order to maintain the uniformity of descriptions. All the statements and developed meanings were checked by other expert who confirmed whether the methods were accurate and consistent or not.

Fourthly, based on the agreement with the developed meanings and concepts, categories, and subcategories of the information, the phenomenon was developed. This phenomenon had given the clear information of the context. This process had combined the similar theme together and developed the common concepts with the discussion of all research members. All the researchers checked the accuracy and clarity of theme and concepts, which were later checked by an expert. The researchers and associates in the area of health research established the richness and reliability of the coding through broad discussions.

\section{Ethical considerations}

The protocol of this study was approved by the institutional ethical review committee of Nobel College, Pokhara University, Nepal. All the interview documents were kept anonymous. Privacy and right to withdrawal were granted to all the participants and key informants. Written consent was taken from both participants and key informants.

\section{Results}

Nearly half of the participants were male, and majority (45\%) were from age group 60-69 years, where $75 \%$ belonged to Hindu religion (Table 1).

This process led to the ultimate reduction of the raw data into three main themes: elderly-friendly services, expectation from government and hospital, and health policy related to senior citizen. The first theme produced nurses' behavior, doctors' behavior, and hospital facilities (available physical facilities and health facilities of hospital known as hospital environment); the second theme produced nutritious food, free medicine, free medical services, and transportation incentives; the third theme produced right to information, 
Table I Demographic characteristics

\begin{tabular}{lll}
\hline Characteristics & Frequency & Percentage \\
\hline Sex & 16 & \\
Male & 17 & 48.48 \\
Female & & 51.51 \\
Age (years) & & \\
Mean \pm SD: $71.52 \pm 6.14$ & 15 & \\
$\geq 60-69$ & 14 & 45.45 \\
$\geq 70-79$ & 4 & 42.42 \\
$\geq 80$ & & 12.12 \\
Religion & 25 & \\
Hindu & 3 & 75.75 \\
Christian & 5 & 9.09 \\
Buddhist & & 15.15 \\
\hline
\end{tabular}

Abbreviation: SD, standard deviation.

information dissemination, older people health card (identification card for older people's health benefits), and advocacy for older people's health (raise the voice from any level for the benefit of older people) (Figure 1). The narrations of the participants according to these three themes are discussed below on the situation of elderly-friendly hospitals in Kathmandu.

\section{Elderly-friendly services}

Nurses' behavior

Most of the older patients were satisfied with the treatment and care of nursing staff. They were helpful, friendly, and had good communication with the older patients. Most of the participants were happy and satisfied with their work and their responsibilities. Patients received the medicine on time and were encouraged to eat healthy foods.

They are doing a holy job. [PT5]

Despite positive compliments, in some cases, nurses showed rude behavior to the patients and caregivers. Sometimes, nurses were unable to give proper attention to the older patients when they called them for help.

When I complained that the toilet was dirty the nurse snapped at me saying that it is cleaner than toilet in your house. [PT (participant) 2]

The nurses are experienced to look after the older patient but none of them have training on geriatric care. [HM (hospital manager) 2]

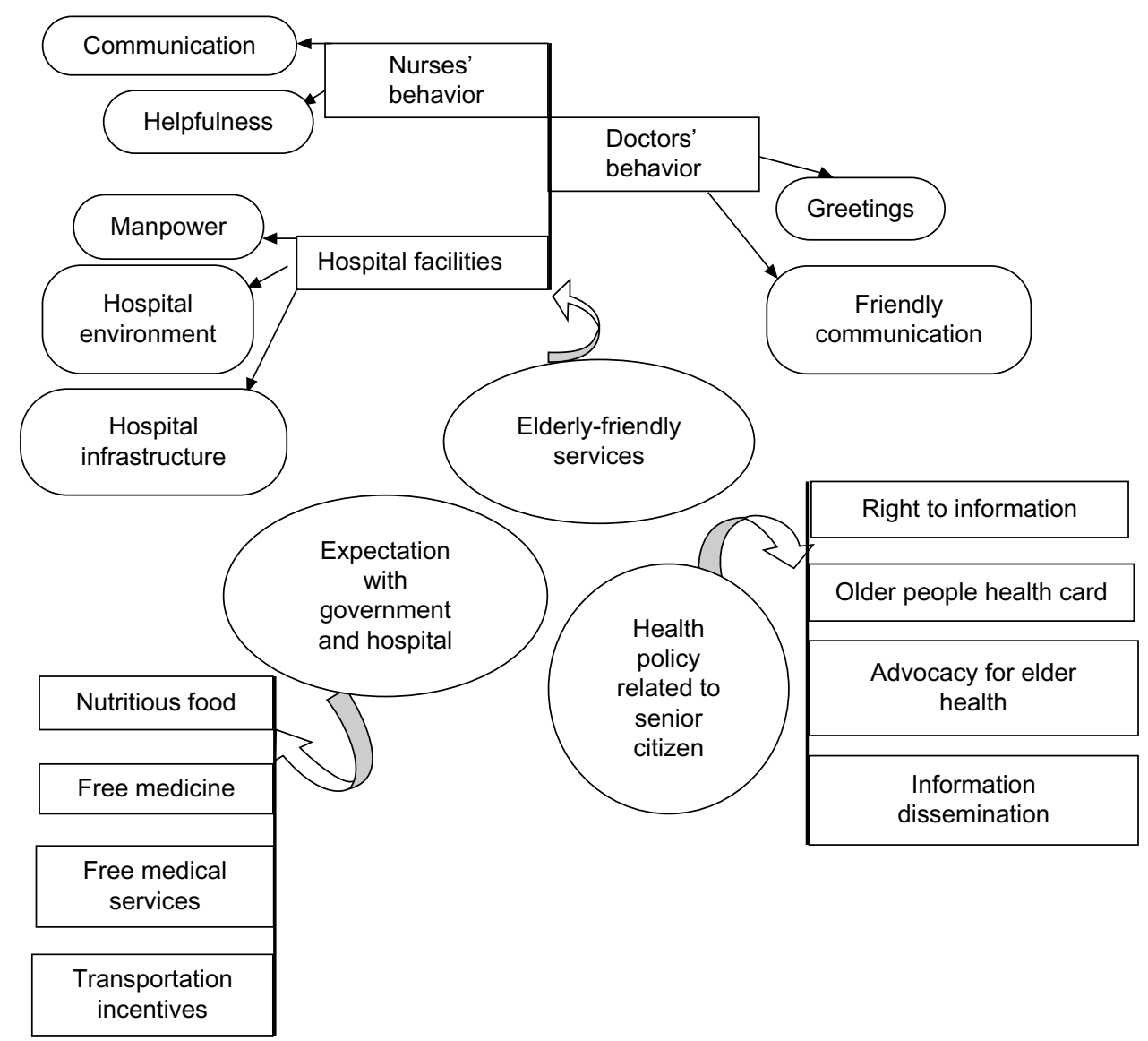

Figure I List of themes. 


\section{Doctors' behavior}

The older participants were highly satisfied with the behavior of the doctors as they used to explain all the processes of treatment and side effects of the medicine in addition to giving motivation to get better soon. In every visit, the doctors used to ask about the improvement in their health and any other problems which made the patients very happy.

Half the disease feels cured when you are asked about our health with a smiley face and soft voice. [PT2]

\section{Hospital facilities}

Most of the participants were not satisfied with available health facilities as they had faced problem due to improper hospital facilities regarding manpower, hospital environment, and hospital infrastructure. Lift and ramp ways are one of the most essential infrastructures that must be present in the hospital.

Hospital had no ramp ways or lift so I had difficulty moving when I was in a wheel chair. [PT6]

Moreover, most of the participants faced common problem related to toilet which was slippery, unhygienic, and dirty. Further, patients also had problem using pan system toilet, especially those who suffered from arthritis. Few of the participants complained that bed covers were not changed on time.

I am an asthma patient so I have difficulty in going to-andfrom the toilet since it is very far. Also, having arthritis it is difficult for me to use the pan system toilet. [PT3]

Most of the older persons are from a village background so they don't know how to use western toilet properly. [HM4]

Hospital ward facilities were not sufficient and appropriate for older patients.

I have requested to be admitted to the ICU but due to unavailability of bed they kept me in a general ward. [PT17]

Most of the male patients expressed discomfort with female nurses as female nurses felt uneasy while caring for the male patients. Female nursing care was perceived negatively by male patients compared to female patients.

It would be easier if there was a male nurse for male patients.

We would receive more attention and care. [PT3]
In addition, most of the participants expect TV for recreation and entertainment. Most of them felt difficulty passing time.

There must be at least a television for the recreation of the patients staying for a longer duration in the hospital. [PT25]

Similarly, majority of the participants faced difficulty on transportation because most of the ambulance services are available in Kathmandu valley which resulted in paying high amount for rural people.

I paid a high amount for transportation. It will be easier if ambulance services are provided to the patient outside the valley. [PT23]

Next, most of the participants wanted to share the room with a person of similar age so that they could have a better conversation with other admitted patients.

It feels easier to talk with a person of the same age and pass the time. [PT13]

We couldn't upgrade our hospital due to the budget constraints. [HM1]

\section{Expectation from government and hospital \\ Nutritious food}

Majority of older patients demanded healthy and safe food from the hospital. They expected safe and clean canteen so that they could consume healthy and safe food during the hospital stay.

We are not able to make food suitable for the patient so the hospital canteen should arrange for safe and healthy food for the patient in the hospital. [PT25]

\section{Free medicine}

Majority of the participants were not able to afford expensive medicine. During treatment, participants expected some sort of concession on medicine so that their illness could be treated properly without any delay and obstacle. On top of that, older people faced difficulty while waiting in a queue to purchase medicine in pharmacy.

Medicines are more expensive than treatment cost in the hospital. [PT31]

I am an arthritis patient. It is difficult for me to stand in a queue for long durations. [PT29]

Government has provision of free medicine for older patients in allocated amounts; we only provide that medicine to older patients. [HM1] 


\section{Free medical services}

Older patients expected free medical services along with concession in medical investigation and surgery.

We had requested for concession in treatment, but still we didn't received any concession from them. [PT22]

Hospital is providing free investigation services in total blood count, ECG, X-RAY, stool and urine test as well 50\% off is given in investigation related to diabetes, heart disease, and thyroid. [HM2]

\section{Transportation incentives}

Majority of the older patients were from outside the Kathmandu valley. They expected free or low-cost transportation facilities from the hospital for the easiness in checkup and follow-up. However, few participants expressed that they did not have any kind of expectations from hospital and the government. Rather, they wanted to recover soon and get discharged from the hospital as their main concern was their own health.

I am already 82 years old, I just want to be treated well, other than this I don't have any expectation from this hospital. [PT31]

We don't have any provision to provide free transportation or incentives for older patient. [HM3]

\section{Health policy related to senior citizen} Right to information

Majority of the participants were not aware about the health services that were provided by hospital or government. Most of them did not know about the free health service provision in government act.

I am a farmer; mostly we are engaged in farming. Hospital authority must be transparent and notify us about all the facilities that are provided by hospital or government. [PT33]

For those who seek information regarding older citizen, we provide full information regarding this context. [HM4]

\section{Information dissemination}

Information dissemination was not satisfactory as most of the participants were unable to get the correct information related to the health services. If proper information was disseminated by the hospital, then services would be received without any trouble.

Every hospital should have a citizen charter so that every individual can get the information though it. [PT29]
We agree we couldn't make the citizen charter about health services in our hospital available for all to see. [HM4]

\section{Older people health card}

Health card plays a vital role in maintaining the history of the patient. Older people health card could help older patients to receive health services in an easier and faster way. Most of the participants expected it from all the hospitals.

It would be easier if we were given separate health card than other age group. It would help in receiving services in easy way. [PT17]

Our hospital does not issue older health card but, if it can issue, it will be easy to provide the health services. [HM2]

\section{Advocacy for older people's health}

Most of the participants were not able to pay their health expenses. They were dependent on their children or were in need of someone's help. Thus, on the basis of personnel experiences and thoughts of the participants, most of the older citizens felt the importance of advocacy.

I have sold all my properties, whatever I had earned during my working years; I have spent it all on my treatment. No one is here to raise voices for older people to the government. [PT5]

I personally want to be involved in raising the voice with older people for right of the older people's health. [HM3]

\section{Triangulation of sources of data}

Key informants reported that they were unable to provide all the facilities to older patients because of the constraints of budget, and unavailability of space for extension of senior ward, outpatient departments, and other facilities. They also notified that government has no transparent policy which is a major obstacle for development. There are no guidelines and policy available that can enhance the skillful manpower in hospital. However, older patients are benefited from hospital services including charity on treatment. Even then, patients were not satisfied upon the given hospital facilities and high cost of the treatment. Older patients reported having different expectations from hospital and government, and even those expectations are beyond the government and hospital policy. Patients were satisfied with the behavior of medical staff during the tenure of the hospital stay.

\section{Discussion}

Findings of this study were based on the information abstracted from older patients, who were admitted in hospital, 
and hospital managers. This study explored the experiences of older patients and views of hospital managers which revealed three main themes and different subthemes related to health manpower, hospital facilities, physical environment, policy, and other general facilities.

This study highlighted that most of the older patients were satisfied with nurses' and doctors' behavior in hospital. Similarly, previous systematic review and experimental study highlighted that the older patients are vulnerable with complex health problems and they need frequent support and care from medical staffs. ${ }^{2,4,5}$ Another study suggested that polite behavior of health professionals could be helpful to reduce health problems and psychological support. ${ }^{29,30}$ This finding is in agreement with this study. None of the health professionals received any training on geriatric care and geriatric medicine so far. However, they are trying to provide necessary services for older patients. Previous literature revealed that the trained health professional could provide good caring and quality services. ${ }^{29}$

Previous studies revealed that the hospital environment could affect the quality of life and functional ability of older patients. ${ }^{2,18-21}$ Hospital environment including toilet, lift and ramps, separate wards for male and female, and pleasing words was commonly desired by older patients. However, hospitalized older patients explained that they did not get such environment in hospital. Similarly, previous study highlighted that toilet, waking surface, light level, and condition of ward were the psychological and motivational factors for older patients. ${ }^{29}$ In our study, key informants notified that physical facilities are constraints and less accessible for older patients in the hospital. Previous studies revealed that the building codes and health service guidelines must be developed by hospitals to maintain senior friendly hospital environment. ${ }^{6,29}$ Other study findings suggested that appropriate hospital environment can increase efficient capacity of older patients. ${ }^{13}$

Older patients have found different expectations from hospitals including free and easy treatment, medicine, transportations, and food. Previous literature supported our finding that affordable care, medical supply, and support were highly expected by older patients..$^{29}$ Older patients were dissatisfied with available transportation systems and have complained of transportation cost. Similar finding was revealed from previous literature that good transportation during illness was highly expected and is an essential requirement for older patients. ${ }^{29}$ The government of Nepal has started provision of free health services for older patients. However, all the hospitals are unable to provide free health services for older patients.
Previous literature highlighted that older patients need to be supported for free health services and income. ${ }^{29}$

Existing findings from Canada highlighted that the policy and guidelines are necessary to maintain the hospital environmental for older patients. ${ }^{11}$ Another study also highlighted the policies related to older patients that need to consider the physical infrastructure of the hospital environments. ${ }^{18}$ However, our study finding revealed that no hospital and government have policy related to elderly-friendly hospital. Studies conducted by Shanley et al and O'Keeffe suggested that every hospital should have its own policies and guidelines for older patients. ${ }^{10,11}$ This study finding suggested that all the hospitals should have transparency in available health services for older patients. Hospitals, non-government organization, government, and individuals need to advocate for elderly-friendly health services.

\section{Strengths, limitations, and future research}

This study has strengths and limitations which may inhibit the generalizabiity of the findings. Participants were recruited using non-probability sampling and could not be representative of the whole target population in terms of demographic variables including education, and cultural factors. Therefore, this study finding may not be applicable for all the older patients. Further, information obtained from the key informants may not be distinctive of all hospitals. We did not exclude the multi-timeadmitted patients in hospital which persist the information bias. Further, we did not consider the length of stay in the hospital. In addition, strength of this study was the rigor and depth analysis conducted by research team members, independently developed theme and concepts, and audition by expert. Next, this study was categorized by four domains (government, community, semi-government, and private), and similar numbers of male and female participants were taken as sample. Future research might be conducted to cover different geographical areas and also use quantitative approach to recognize the occurrence of these values in diverse populations. In addition, clinical staffs' opinion would be more beneficial in the future research.

\section{Trustworthiness of the study findings}

Validity and reliability of the qualitative research comprised the strength of the data collection, data analysis, and descriptions. Pilot study had increased the credibility of the study through the redesigned interview guidelines. Theme and concepts were developed after an agreement among different research members and validated by expert. Coding process, analysis, and descriptions were checked by other experts, while cross checking was done by the supervisor. 


\section{Conclusion}

We found different issues including policies, physical environments, elderly-friendly health manpower, health cards, and other facilities and benefits. This study's findings advance that there is an essential requirement to be aware of experiences and desires of the older people, and thus to grow agendas for this population that can effectively promote elderly-friendly hospitals and health services for all Nepalese older people, especially for the high-risk and vulnerable group. These agendas should focus on addressing the elderly-friendly hospital policies and guidelines, health benefits, and friendly services.

\section{Acknowledgments}

The authors would like to thank the elderly patients and hospital managers who participated in this study. They are grateful for the assistance of hospital authorities. They would like to thank Shristi Khadka for her support in sentence structuring and grammatical correction.

\section{Authors' contributions}

All authors contributed toward data analysis, drafting, and critically revising the paper and agree to be accountable for all aspects of the work.

\section{Disclosure}

The authors declare that they have no competing interests.

\section{References}

1. United Nations (UN). Department of Economic and Social Affairs, Population Division World Population Ageing; 2013. Available from: http://wwwunorg/en/development/desa/population/publications/pdf/ ageing/WorldPopulationAgeing2013pdf.

2. Hickman L, Newton P, Halcomb EJ, Chang E, Davidson P. Best practice interventions to improve the management of older people in acute care settings: a literature review. $J$ Adv Nurs. 2007;60: 113-126.

3. Baztán JJ, Suárez-García FM, López-Arrieta J, Rodríguez-Mañas L, Rodríguez-Artalejo F. Effectiveness of acute geriatric units on functional decline, living at home, and case fatality among older patients admitted to hospital for acute medical disorders: meta-analysis. BMJ. 2009;338:b50.

4. Saltvedt I, Spigset O, Ruths S, Fayers P, Kaasa S, Sletvold O. Patterns of drug prescription in a geriatric evaluation and management unit as compared with the general medical wards: a randomised study. Eur $J$ Clin Pharmacol. 2005;61:921-928.

5. Counsell SR, Holder CM, Liebenauer LL, et al. Effects of a multicomponent intervention on functional outcomes and process of care in hospitalized older patients: a randomized controlled trial of acute care for elders (ACE) in a community hospital. J Am Geriatr Soc. 2000;48: $1572-1581$.

6. Wong K, Liu B. The Regional Geriatric Program of Toronto. A Summary of Senior Friendly Care in Toronto Central LHIN Hospitals. Toronto: Toronto Central Local Health Integration Network; 2011.
7. Ducharme F, Couture M, Lamontagne J. Decision-making process of family caregivers regarding placement of a cognitively impaired elderly relative. Home Health Care Serv Q. 2012;31:197-218.

8. O'Connor AM, Stacey D, Légaré F. Coaching to support patients in making decisions. $B M J$. 2008;336:228.

9. Beswick AD, Rees K, Dieppe P, et al. Complex interventions to improve physical function and maintain independent living in elderly people: a systematic review and meta-analysis. Lancet. 2008;371:725-735.

10. Shanley C, Sutherland S, Stott K, Tumeth R, Whitmore E. Increasing the profile of the care of the older person in the ED: a contemporary nursing challenge. Int Emerg Nurs. 2008;16:152-158.

11. O'Keeffe J. Creating a senior-friendly physical environment in our hospitals. Geriatr Today. 2004;7:49.

12. Hwang U, Morrison RS. The geriatric emergency department. $J$ Am Geriatr Soc. 2007;55:1873-1876.

13. Covinsky KE, Palmer RM, Fortinsky RH, et al. Loss of independence in activities of daily living in older adults hospitalized with medical illnesses: increased vulnerability with age. J Am Geriatr Soc. 2003;51: 451-458.

14. Sager MA, Franke T, Inouye SK, et al. Functional outcomes of acute medical illness and hospitalization in older persons. Arch Intern Med. 1996;156:645-652.

15. Dady KF, Rugg S. An exploration of individuals' expectations of their stay on an elderly care unit. Br J Occup Ther. 2000;63:9-16.

16. Douglas $\mathrm{CH}$, Douglas MR. Patient-friendly hospital environments: exploring the patients' perspective. Health Expect. 2004;7:61-73.

17. Kihlgren AL, Nilsson M, Skovdahl K, Palmblad B, Wimo A. Older patients awaiting emergency department treatment. Scand J Caring Sci. 2004;18:169-176.

18. Parke B, Hunter K. A pattern of care transitions for older adults: a gerontological nursing perspective. Can Gerontol Nurse. 2009;24:18-21.

19. Ellis G, Whitehead MA, O'Neill D, Langhorne P, Robinson D. Comprehensive geriatric assessment for older adults admitted to hospital. Cochrane Database Syst Rev. 2011;7:CD006211.

20. Arora VM, Johnson M, Olson J, et al. Using assessing care of vulnerable elders quality indicators to measure quality of hospital care for vulnerable elders. J Am Geriatr Soc. 2007;55:1705-1711.

21. Parke B, Chappell NL. Transactions between older people and the hospital environment: a social ecological analysis. J Aging Stud. 2010;24:115-124.

22. Finucane P, Wundke R, Whitehead C, Williamson L, Baggoley C. Use of in-patient hospital beds by people living in residential care. Gerontology. 2000;46:133-138.

23. Ouslander JG, Lamb G, Perloe M, et al. Potentially avoidable hospitalizations of nursing home residents: frequency, causes, and costs. J Am Geriatr Soc. 2010;58:627-635.

24. Legler CF, Cawley JF, Fenn WH. Physician assistants: education, practice and global interest. Med Teach. 2007;29:e22-e25.

25. GoN. Senior Citizens Act 2006. Government of Nepal (GoN); 2006. Available from: http://www.lawcommission.gov.np/site/sites/default/ files/Documents/Senior\%2BCitizens\%2BRules.pdf.

26. Graneheim UH, Lundman B. Qualitative content analysis in nursing research: concepts, procedures and measures to achieve trustworthiness. Nurse Educ Today. 2004;24:105-112.

27. Colaizzi PF. Psychological research as the phenomenologist views it. In: Valle K, King M, editors. Phenomenological Alternatives for Psychology. New York: Oxford University Press; 1978:48-71.

28. NVivo Qualitative Data Analysis Software. QSR International Pty Ltd. Version 8; 2010.

29. WHO. Global Age-friendly Cities: A Guide. World Health Organization; 2007. Available at http://www.who.int/ageing/publications/Global_age_ friendly_cities_Guide_English.pdf. Accessed April 15, 2015.

30. Légaré F, Stacey D, Brière N, et al. An interprofessional approach to shared decision making: an exploratory case study with family caregivers of one IP home care team. BMC Geriatr. 2014;14:83. 
Risk Management and Healthcare Policy

Dovepress

\section{Publish your work in this journal}

Risk Management and Healthcare Policy is an international, peerreviewed, open access journal focusing on all aspects of public health, policy, and preventative measures to promote good health and improve morbidity and mortality in the population. The journal welcomes submitted papers covering original research, basic science, clinical \& epidemio- logical studies, reviews and evaluations, guidelines, expert opinion and commentary, case reports and extended reports. The manuscript management system is completely online and includes a very quick and fair peerreview system, which is all easy to use. Visit http://www.dovepress.com/ testimonials.php to read real quotes from published authors.

Submit your manuscript here: http://www.dovepress.com/risk-management-and-healthcare-policy-journal 